\title{
INTERFERÊNCIA DO pH INICIAL E VOLUME DE MEIO NA PRODUÇÃO DE CAROTENOIDES POR Sporidiobolus pararoseus
}

\author{
M. N. TAVARES ${ }^{1}$, C. S. SÁ ${ }^{1}$, C. M. BORBA ${ }^{1}$, C. C.MORAES ${ }^{2}$ e J. F. M. BURKERT ${ }^{1}$ \\ ${ }^{1}$ Universidade Federal do Rio Grande, Escola de Química e Alimentos \\ ${ }^{2}$ Universidade Federal do Pampa, Curso de Engenhara de Alimentos \\ E-mail para contato: carinamolinsborba@yahoo.com.br
}

\begin{abstract}
RESUMO - Fatores como composição do meio, temperatura, aeração e pH podem interferir na produção de microbiana de carotenoides. Em vista disso, o presente trabalho teve como objetivo avaliar o efeito do $\mathrm{pH}$ inicial (3 à 5) e a relação de volume de meio para volume de reator (3:10 à 7:10) no cultivo em frascos agitados para produção de carotenoides por $S$. pararoseus. Na faixa estudada, apenas a variável $\mathrm{pH}$ presentou um efeito significativo $(\mathrm{p}<0,05)$ sobre a resposta carotenoides totais. O valores máximo de carotenoides totais alcançados foram de 204,7 (ensaio 2) a 463,9 $\mu \mathrm{g} / \mathrm{L}$ (ensaio 1) e para biomassa de 4,6 (ensaio 4) a 13,6 $\mathrm{g} / \mathrm{L}$ (ensaio 1), sendo que os menores valores na produção de carotenoides e de biomassa ocorreram nos ensaios com $\mathrm{pH}$ 5,0 (nível +1). A produção em $\mathrm{pH}$ próximo a 3 levou a uma aumento e aproximadamente $56 \%$ na produção de carotenoides e $66 \%$ na biomassa foi produzida nesse $\mathrm{pH}$ do que em comparação ao $\mathrm{pH} 5$.
\end{abstract}

\section{INTRODUÇÃO}

Os carotenoides estão amplamente distribuídos na natureza, apresentando papel de destaque na fotossíntese e fotoproteção de sistemas vegetais e como precursores de vitamina A nos seres humanos. Além de funções nos sistemas biológicos, apresentam também grande importância para a indústria farmacêutica na elaboração de cosméticos e como aditivo alimentar na indústria de alimentos (DAMODARAN, et al., 2010).

Diversos estudos demonstram que a composição do meio empregado pode interferir na bioprodução desses pigmentos, além disso, outras condições externas do cultivo como temperatura, agitação, aeração e pH também levam a alterações como variedade e quantidade de carotenoides produzidos pelo micro-organismo (RIBEIRO, et al., 2011; SCHWARTZ, 2010).

Em vista do apresentado o presente trabalho possui como objetivo avaliar a interferência do $\mathrm{pH}$ inicial e a relação Vmeio:Vreator na produção de carotenoides por Sporidiobolus pararoseus em frascos agitados

\section{MATERIAL E MÉTODOS}




\subsection{Preparo do inóculo e Bioprodução}

Para a reativação, foram realizados repiques a partir das culturas estoques contendo o mesmo meio e incubados por $48 \mathrm{~h} \mathrm{a} 25^{\circ} \mathrm{C}$. Aos tubos de reativação foram adicionados $1 \mathrm{~mL}$ de água peptonada $(0,1 \%)$ para ressuspensão da biomassa, posteriormente adicionada em $9 \mathrm{~mL}$ de caldo composto por $40 \mathrm{~g} / \mathrm{L}$ de melaço e 6,5 g/L de água de maceração de milho, prétratado com ácido sulfúrico segundo Machado (2013), sendo incubados nas mesmas condições descritas anteriormente. $\mathrm{O}$ inóculo foi preparado em frascos agitados de $250 \mathrm{~mL}$ contendo $90 \mathrm{~mL}$ do meio já citado anteriormete, adicionado de $10 \mathrm{~mL}$ de cultivo oriundo da reativação, sendo incubados a $180 \mathrm{rpm}, 25^{\circ} \mathrm{C}$ por $48 \mathrm{~h}$, ou tempo necessário para concentração celular atingir $1 \times 10^{7}$ células $/ \mathrm{mL}$, contadas através de câmara de Neubauer.

Os ensaios de bioprodução foram realizados Erlenmeyers de $500 \mathrm{~mL}$ à150 rpm, $27,5^{\circ} \mathrm{C}$ por $240 \mathrm{~h}$, com acompanhamento de biomassa $(\mathrm{g} / \mathrm{L})$ através de uma curva padrão, $\mathrm{pH}$ em potenciômetro, açúcares redutores totais - ART (g/L) pelo método DNS (MILLER, 1959) com curva padrão de glicose e hidrólise ácida das amostras e carotenoides totais $(\mu \mathrm{g} / \mathrm{L})$. Os valores de $\mathrm{pH}$ e volume de meio foram definidos através de um planejamento experimental $2^{2}$ com 3 pontos centrais (Tabela 1).

\subsection{Rompimento celular e obtenção dos extratos carotenogênicos}

Para a determinação da concentração de carotenoides a biomassa foi seca por $48 \mathrm{~h}$ a $35^{\circ} \mathrm{C}$, macerada em gral, padronizada em peneira com mesh 115 (CIPOLATTI, 2012) e congeladas por $48 \mathrm{~h}$. Para o rompimento celular $0,05 \mathrm{~g}$ de biomassa foram adicionados de 2 $\mathrm{mL}$ de DMSO a $55^{\circ} \mathrm{C}$ e homogeneizadas por $1 \mathrm{~min}$ em vórtex, em intervalos de tempo de 15 min, até completar um período de $1 \mathrm{~h}$ de contato (FONSECA et al., 2011). Após a ruptura foram adicionados $6 \mathrm{~mL}$ de acetona, a fim de promover a extração dos carotenoides. A amostra foi centrifugada a $1745 \mathrm{xg}$ por $10 \mathrm{~min}$, a fase solvente separada e o procedimento de ruptura repetido até o branqueamento total das célula. Aos sobrenadantes foram adicionados $10 \mathrm{~mL}$ de solução de $\mathrm{NaCl} 20 \%\left(\mathrm{p} \cdot \mathrm{v}^{-1}\right)$ e $10 \mathrm{~mL}$ de éter de petróleo. Após a formação de duas fases a fase apolar foi filtrada com sulfato de sódio $\left(\mathrm{Na}_{2} \mathrm{SO}_{4}\right)$, dando origem aos extratos carotenogênicos (MICHELON, et al., 2012).

\subsection{Determinação de carotenoides totais}

A determinação da concentração de carotenoides totais nos extratos foi realizada em espectrofotômetro (Biospectro SP-220) através do valor médio da máxima absorbância a 448 $\mathrm{nm}$, utilizando a Equação 1, e sendo expresso em termos de seu carotenoide majoritário ( $\beta$ caroteno em éter de petróleo com absortividade especifica de $=2592$ ) de acordo com Davies (1976).

$$
C T=\frac{A * V * 10^{6}}{A_{1 \mathrm{~cm}}^{1 \%} * 100 * m_{\text {amostra }}}
$$

Onde: $\mathrm{CT}=$ concentração específica de carotenoides de totais $(\mu \mathrm{g} / \mathrm{g}) ; \mathrm{A}=$ absorvância; $\mathrm{V}=$ volume $(\mathrm{mL}) ; \quad \mathrm{m}_{\text {amostra }}=$ massa celular seca $(\mathrm{g}) ; \mathrm{A}_{1 \mathrm{~cm}}{ }^{1 \%}=$ absortividade específica. Os valores de carotenoides totais foram convertidos à valores de carotenoides totais $(\mu \mathrm{g} / \mathrm{L})$ utilizando-se a concentração de biomassa $(\mathrm{g} / \mathrm{L})$. 


\section{RESULTADOS E DISCUSSÃO}

$\mathrm{Na}$ Tabela 1 estão apresentados os valores codificados e reais das variáveis independentes $\mathrm{pH}$ e relação Vmeio:Vreator e as respostas em carotenoides totais. Considerando as variáveis $\mathrm{pH}$ e Vmeio:Vreator, foi realizada a verificação do modelo de primeira ordem analisando a resposta carotenoides totais.

Para verificação do modelo foram calculados os efeitos, erro padrão, limites de confiança e os coeficientes de regressão (Tabela 2). A análise de anova também foi realizada

Tabela 1- Delineamento experimental $2^{2}$ (valores codificados e reais) e valores para resposta carotenoides totais

\begin{tabular}{cccc}
\hline Ensaio & $\mathbf{X}_{\mathbf{1}}$ & $\mathbf{X}_{\mathbf{2}}$ & $\begin{array}{c}\text { Carotenoides } \\
\text { Totais }(\mu \mathrm{g} / \mathrm{L})\end{array}$ \\
\hline $\mathbf{1}$ & $-1,00(3)$ & $-1,00(3: 10)$ & 463,9 \\
$\mathbf{2}$ & $1,00(5)$ & $-1,00(3: 10)$ & 204,7 \\
$\mathbf{3}$ & $-1,00(3)$ & $1,00(7: 10)$ & 468,4 \\
$\mathbf{4}$ & $1,00(5)$ & $1,00(7: 10)$ & 265,8 \\
$\mathbf{5}$ & $0(4)$ & $0(1: 2)$ & 338,9 \\
$\mathbf{6}$ & $0(4)$ & $0(1: 2)$ & 337,7 \\
$\mathbf{7}$ & $0(4)$ & $0(1: 2)$ & 426,7 \\
\hline \multicolumn{4}{c}{$\mathrm{X}_{1}: \mathrm{pH}$ inicial; $\mathrm{X}_{2}: \mathrm{V}_{\text {meio }}: \mathrm{V}_{\text {reator }}$}
\end{tabular}

Tabela 2- Efeito, erro padrão, limites de confiança e coeficiente de regressão do modelo linear

\begin{tabular}{ccccccc}
\hline \multicolumn{7}{c}{${\text { Carotenoides Totais }\left(\boldsymbol{\mu g . \mathbf { L } ^ { - 1 }}\right)}$} \\
\hline & Efeito & $\mathbf{E P}$ & $\mathbf{t}(\mathbf{3})$ & $\mathbf{p}$ & Coeficiente de Regressão $_{c}$ & $\mathbf{p}$ \\
\cline { 2 - 7 } Média & 358,0 & 16,5 & 21,7 & $\mathrm{p}<0,01$ & 358 & $<0,01$ \\
$\mathbf{X}_{\mathbf{1}}(\mathbf{L})^{*}$ & $-230,9$ & 43,6 & $-5,3$ & 0,01 & 230,9 & $<0,01$ \\
$\mathbf{X}_{\mathbf{2}}(\mathbf{L})$ & 32,8 & 43,6 & 0,7 & 0,51 & & \\
$\mathbf{X}_{\mathbf{1}} \mathbf{X}_{\mathbf{2}}$ & 28,3 & 43,6 & 0,6 & 0,56 & & \\
\hline
\end{tabular}

Carotenoides Totais $=358-230,4 * \mathrm{pH}$

Apenas a variável $\mathrm{pH}$ apresentou efeito significativo sobre a produção de carotenoides totais dentro da faixa estudada. Sendo que a mudança do $\mathrm{pH}$ do nível -1 para +1 acarretou um decréscimo de aproximadamente $115 \%$ na resposta. Para uma possível observação do efeito do volume de meio sobre a reposta seria necessário uma ampliação na faixa estudada.

Através da curva de contorno obtida, torna-se mais fácil perceber que, indiferentes do volume de meio utilizados, quanto mais próximo o valor de $\mathrm{pH}$ está do nível -1 melhores os resultados obtidos. A equação 2 é o modelo matemático para carotenoides totais. Os valores máximos de carotenoides totais variaram entre 204,7 (ensaio 2) a 463,9 $\mu \mathrm{g} / \mathrm{L}$ (ensaio 1). Já os valores de biomassa máxima variaram entre 4,6 (ensaio 4) a 13,6 g/L (ensaio 1). Os menores valores na produção de carotenoides e de biomassa ocorreram nos ensaios com $\mathrm{pH}$ no nível $+1(5,0)$, sendo que no ensaio 4 , onde a produção de biomassa foi a menor de todas, além do 
pH 5 a relação $\mathrm{V}_{\text {meio }}: \mathrm{V}_{\text {reator }}$ estava no nível +1 (350 $\mathrm{mL}$ de meio). Esse volume de meio mais elevado, provavelmente levou a uma maior dificuldade na dissolução do oxigênio no meio diminuindo a taxa de transferência de oxigênio (OTR).

Figura 1- Curvas de contorno para produção de carotenoides totais

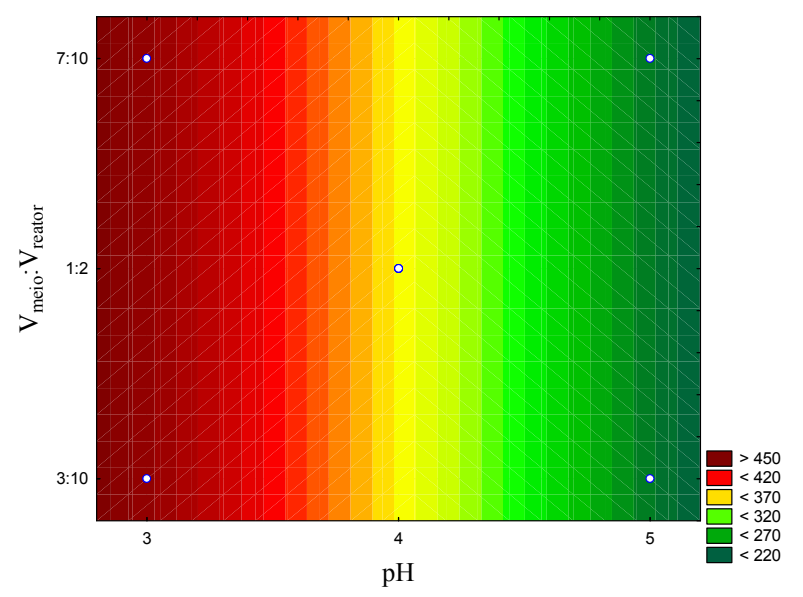

Uma aeração suficiente parece ser de extrema importância para o progresso da produção, sendo um pré-requisito para a produção satisfatória de $\beta$-caroteno. Assim sendo, um certo nível de stress oxidativo auxilia na produção de carotenoides, visto que estimula a produção de compostos antioxidantes como o $\beta$-caroteno. Porém valores de OTR muito altos podem acarretar a oxidação desses pigmentos, resultando em menores valores de produtividade (MANTZOURIDOU, et al.,2005).

Os valores mais elevados para as duas respostas foram encontrados no ensaio 5, onde o $\mathrm{pH}$ e a relação $\mathrm{V}_{\text {meio }}: \mathrm{V}_{\text {reator }}$ foram mantidos no ponto central ( $\mathrm{pH} 4$ e $250 \mathrm{~mL}$ de meio). $\mathrm{Na}$ Figura 2 está apresentado o acompanhamento cinético dos cultivos através dos valores de biomassa (a), pH (b), ART (c) e carotenoides totais (d). Os ensaios 1, 3 e 5 apresentam mudanças de $\mathrm{pH}$ pouco acentuadas, sendo que os ensaios 2 e 4 essas mudanças foram mais perceptíveis, Esses dois ensaios apresentaram um consumo de substrato superior a $60 \%$ nas primeiras 24 horas e os menores valores de biomassa, podendo essas três observações estarem relacionadas.

Durante o estudo da produção de carotenoides por S. salmonicolor (CBS 2636) em dois meio de cultivo, uma meio sintético e outro agroindustrial (5 g.L.- água de maceração de milho, 10 g.L - $^{-1}$ de melaço e 5 g.L L $^{-1}$ de hidrolisado de levedura - Prodex Lac () ), os autores perceberam que em aproximadamente $100 \mathrm{~h}$, ponto onde ocorreram as maiores produções de carotenoides $\left(913 \mu \mathrm{g} . \mathrm{L}^{-1}\right.$ para o meio sintético e $502 \mu \mathrm{g} . \mathrm{L}^{-1}$ para o meio agroindustrial), as concentrações de glicose era de 20 e 0,2 g. $\mathrm{L}^{-1}$, para o meio sintético e agroindustrial, respectivamente. $\mathrm{O} \mathrm{pH}$ do meio sintético apresentou pouca variação (de 4 para 3,7) enquanto que o meio agroindustrial apresentou uma elevação considerável de 4 para 8,5, comportamento semelhante ao observado no presente trabalho. Os autores relacionam essas alterações de $\mathrm{pH}$ a uma possível proteólise das células, um fenômeno natural devido a escassez de substrato e consequente degradação dos aminoácidos, o que leva a liberação de compostos amoníacos que elevam o $\mathrm{pH}$ a faixas alcalinas, principalmente quando o micro- 
organismo não possui capacidade de assimilar outra fonte de carbono (VALDUGA, et al. 2009).

Figura 2- acompanhamento cinético dos ensaios do delineamento composto central $2^{2}$ : biomassa (a), pH (b), ART (c) e carotenoides totais (d)

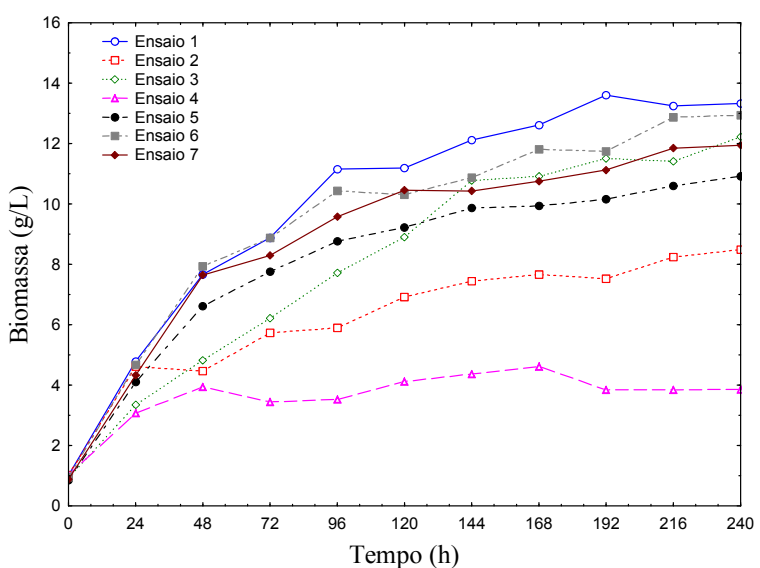

(a)

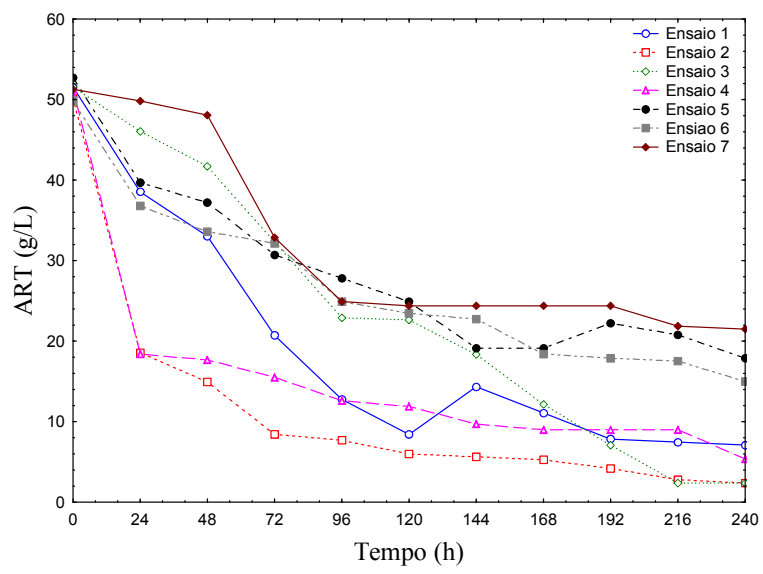

(c)

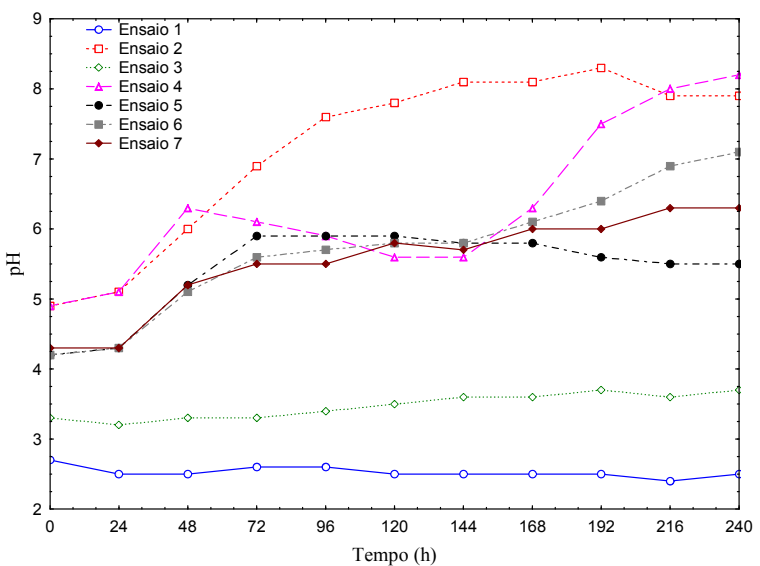

(b)

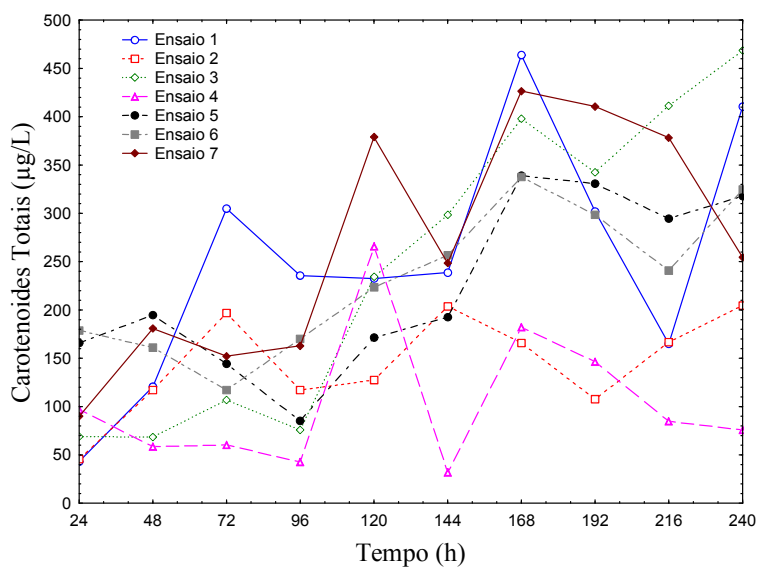

(d)

\section{CONCLUSÃO}

Os valores máximos de carotenoides totais variaram entre 204,7 (ensaio 2) a 463,9 $\mu \mathrm{g} / \mathrm{L}$ (ensaio 1). Já os valores de biomassa máxima variaram entre 4,6 (ensaio 4) a 13,6 g/L (ensaio 1). Foi possível perceber que, a produção em $\mathrm{pH}$ próximo de 3 levou a uma aumento e aproximadamente $56 \%$ na produção de carotenoides e $66 \%$ mais biomassa foi produzida nesse $\mathrm{pH}$ do que em comparação ao pH 5. 


\section{REFERÊNCIAS BIBLIOGRÁFICAS}

CIPOLATTI, E. P. Obtenção de carotenoides microbianos com atividade antioxidante a partir de coprodutos agroindustriais. 2012. 120f. Dissertação (Mestrado em Engenharia e Ciência de Alimentos) - Universidade Federal do Rio Grande, Rio Grande, 2012.

DAMODARAM, S.; PARKIN, K. L.; FENNEMA, O. R. Química de Alimentos de Fennema. 4.ed. - Porto Alegre: Artmed, 2010.

DAVIES, B. H. Chemical Biochemistry Plant Pigments. GOODWIN, T. W., Academic Press: New York, 1976.

FONSECA, R. A. S.; RAFAEL, R. S.; KALIL, S. J.; BURKERT, A. V.; BURKERT, J. F. M. Different cell disruption methods for astaxanthin recovery by Phaffia rhodozyma. African Journal of Biotechnology, v. 10, n. 7, p. 1165-1171, 2011.

MACHADO, W. R. C. Otimização da produção de carotenoids por Sporidiobolus pararoseus e influência de pré tratamentos nos meios de cultivos agrodindustriais. 2013.90 f. Dissertação (Mestrado em Engenharia e Ciência de AlimentosO - Universidade Federal do Rio Grande, Rio Grande, 2013.

MANTZOURIDOU, F.; ROUKAS, T. ACHATZ, B. Effect of oxygen transfer rate on $\beta$-carotene poduction from synthetic médium by Blakeslea trispora in shake flask culture. Enzyme and Microbial Technology, v. 37, p. 687-694, 2005.

MICHELON, M.; de BORBA, T. de M.; RAFAEL, R. da S.; BURKERT, C. A. V.; BURKERT, J. F. de M. Extration of carotenoids from Phaffia rhodozyma: A comparison between different techniques of cell disruption. Food Science and Biotechnology, v. 21, n. 1, p. 1-8; 2012

MILLER, G. L. Use of dinitrosalicylic acid reagent for determination of reducing sugar. Analytical Chemistry, v. 31, n. 3, p. 426-428, 1959.

RIBEIRO, B. D.; BARRETO, D. W.; COELHO, M. A. Z. Technological Aspects of $\beta$-Carotene Production. Food Bioprocess Technology, v. 4, p. 693-701, 2011.

SCHWARTZ, C. R. M. Otimização da produção de carotenoides em meio sintético por Sporidiobolus salminicolor CBS 2636 em biorreator. 2010. 100 f. Dissertação (Mestrado em Engenharia de Alimentos)- Universidade Regional Integrada do Alto Uruguai e das Missões, Erechim, 2010.

VAlDUGA, E, VAlERIO, A., TREICHEL, H., FURIGO, A.J., Di LUCCIO, M., Kinetic and stoichiometric parameters in the production of carotenoids by Sporidiobolus salmonicolor (CBS 2636) in synthetic and agroindustrial media. Applied Biochemistry and Biotechnology, v. 157, p. 61-69, 2009. 